\title{
NON-PERFORATING CYCLODIATHERMY WITH CYCLODIALYSIS CIRCUMSCRIPTA IN GLAUCOMA*
}

\author{
BY \\ V. С̆AVKA \\ Sarajevo, Yugoslavia
}

PERFORATING cyclodiathermy in the surgical treatment of glaucoma was first described by Vogt (1936); this was soon followed by the use of non-perforating cyclodiathermy, which had been first applied by Weve (1933) in a case of hydrophthalmos. Rankin (1942) applied non-perforating cyclodiathermy in cases of absolute glaucoma, between the four rectus muscles and just afterwards Albaugh and Dunphy (1942) performed non-perforating cyclodiathermy in some special cases of glaucoma (Spaeth, 1948). My first observations (Cavka, 1944) were published after I had carried out non-perforating cyclodiathermy combined with iridodialysis in five cases of absolute glaucoma and four of chronic glaucoma. The results were satisfactory inasmuch as the intra-ocular pressure became normal in every case. Post-operative complications included two cases of hyphaema in the anterior chamber, which resorbed totally within a few days, and one case of diathermal retinitis in the area of the ora serrata, which was still visible 6 months later.

Weekers and Weekers (1945) describe a method of non-perforating cyclodiathermy, which they carried out at eight points in the area of pars plana of the ciliary body, $7 \mathrm{~mm}$. from the limbus. In this way they operated on twenty cases of essential glaucoma, and 22 of secondary glaucoma. They succeeded in bringing the intra-ocular pressure to normal in 24 of their 42 cases, some of which were under observation 2 years-after the operation. Weekers, Weekers, and Heintz (1949) state that intra-ocular pressure became normal in 38 (68 per cent.) of 56 glaucomatous eyes operated upon by this method.

Further, Dominguez (1948) applied non-perforating cyclodiathermy nasally in fourteen cases of glaucoma and observed a reduction of the intra-ocular pressure in 50 per cent. In another 25 cases of different forms of glaucoma, he combined non-perforating cyclodiathermy with cyclodialysis. By this method he achieved satisfactory results in six cases of chronic glaucoma, six cases of absolute glaucoma, and two cases of acute glaucoma, but no

* Received for publication November 17, 1950. 
reduction of the intra-ocular pressure was gained in three cases of infantile glaucoma. Desvignes and Naudin (1948) observed a reduction of the intra-ocular pressure after applying non-perforating cyclodiathermy in two cases each of infantile, haemorrhagic, and secondary glaucoma; but no reduction occurred in three cases of absolute glaucoma. Grüter (1949) performed a non-perforating cyclodiathermy in the temporal part of the ciliary body in seventeen cases of primary glaucoma and in fifteen of them he found a reduction of the intra-ocular pressure four months later. Marr (1949) performed non-perforating cyclodiathermy on 57 different forms of glaucoma but concluded that this method is seldom effective in cases of chronic glaucoma.

In the course of my more recent applications of non-perforating cyclodiathermy, certain modifications of my first method were evolved, the chief difference being that iridodialysis was replaced by cyclodialysis circumscripta.

\section{TECHNIQUE}

After the usual anaesthesia an incision is made in the bulbar conjunctiva, from 3 to 9 o'clock, $5 \mathrm{~mm}$. from the limbus (Fig. 1). The conjunctiva has to be separated throughout this region, and four sutures are pulled through the margin of the incision. Then a muscle hook is placed beneath the superior rectus to facilitate the fixation of the eyeball during the performance of cyclodiathermy. This is applied in three horizontal and four vertical lines from 2.5 to $8 \mathrm{~mm}$.. from the corneal limbus (Fig. 2). 50 milliamps are used, each application lasting one second and being made with a ball electrode $1.5 \mathrm{~mm}$. in diameter. After the non-perforating cyclodiathermy comes the surgical cyclodialysis circumscripta; a linear incision is made in the sclera $2 \mathbf{m m}$.

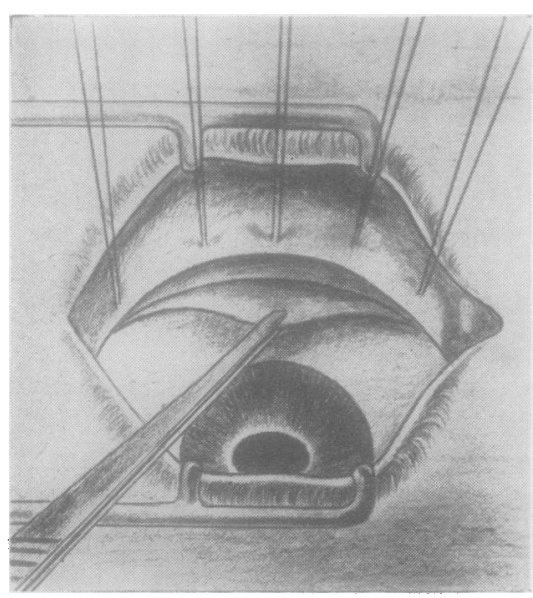

FIG. 1.-Incision into conjunctiva from 3 to 9 o'clock with sutures pulled through. from the corneal limbus at 12 o'clock,

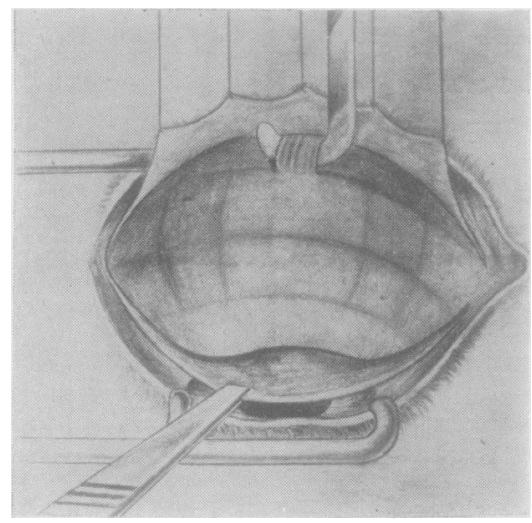

Fig. 2.-Diagram of diathermic rays. 
and the cyclodialysis circumscripta is done through this scleral opening (Fig. 3) from 11.30 to 2.30 o'clock. In particular cases with very greatly increased intraocular pressure, instead of this linear incision the sclera is trephined, as in Elliot's operation, and the cyclodialysis circumscripta is done through the trephine. Post-operatively we use drops about 5 per cent. Targesin and 1 per cent. ung. atrop.

Altogether 43 patients were operated upon, thirty cases of primary and thirteen of secondary glaucoma. In ten cases the operation was performed on both eyes, so that altogether 53 eyes were operated upon. To compare the effect of our technique with other anti-glaucomatous operations (e.g., Elliot's trephine of the sclera, and iridencleisis), we sometimes used our method on one eye and one of the other methods on the second eye. The results obtained from the use of two different methods in these cases will be reported in a subsequent communication.

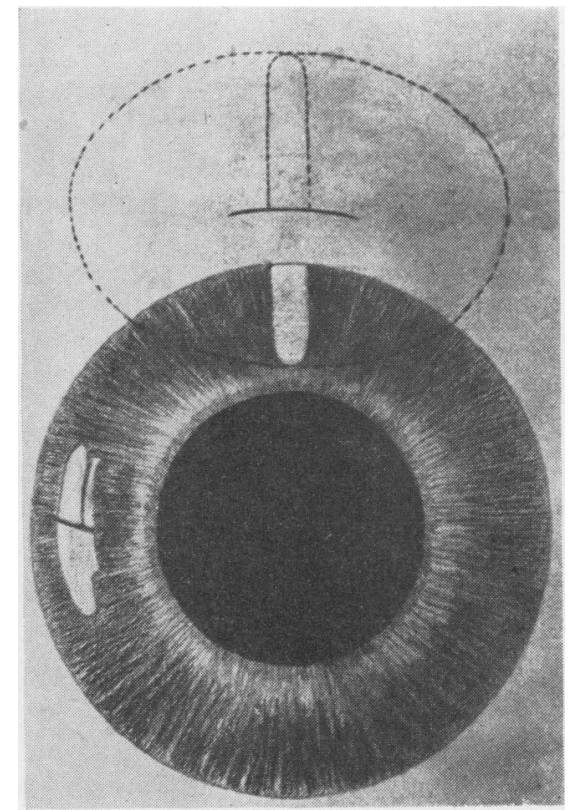

Fig. 3.-Method of performing cyclodialysis circumscripta.

\section{Results}

The success of our method in reducing the intra-ocular pressure to normal in particular forms of glaucoma is apparent from Table I, which shows that, out of 53 eyes, 41 ( 76 per cent.) were made normal. Even in the remaining twelve eyes, a reduction in pressure was

TABLE I

EFFECTS ON INTRA-OCULAR PRESSURE

\begin{tabular}{|c|c|c|c|c|}
\hline \multirow{2}{*}{\multicolumn{2}{|c|}{ Type of Glaucoma }} & \multirow{2}{*}{$\begin{array}{c}\text { Operated } \\
\text { Eyes }\end{array}$} & \multicolumn{2}{|c|}{$\begin{array}{c}\text { Post-operative } \\
\text { Intra-ocular Pressure }\end{array}$} \\
\hline & & & Normal & Not Normal \\
\hline 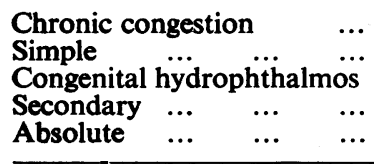 & $\begin{array}{l}\cdots \\
\cdots \\
\cdots \\
\cdots \\
\cdots\end{array}$ & $\begin{array}{r}5 \\
16 \\
4 \\
10 \\
18\end{array}$ & $\begin{array}{r}4 \\
11 \\
4 \\
10 \\
12\end{array}$ & $\frac{1}{5}$ \\
\hline Total & $\ldots$ & 53 & 41 & 12 \\
\hline
\end{tabular}


observed in every case; in most of these the diminution was as much as 20,30 , or $40 \mathrm{~mm}$. It must be emphasized that this method was effective not only in simple and chronic glaucoma but also in absolute and in secondary glaucoma. Moreover, in three cases of absolute glaucoma, even where the intra-ocular pressure was not reduced to normal, a considerable reduction was achieved.

Post-Operative Complications.- In these observations we included all possible changes in the eyes after the operation. Thus the beginning of bleeding in the anterior chamber was noticed as well as the appearance of iritis.

Hyphaema.-This was observed in the anterior chamber, 2 to $3 \mathrm{~mm}$. vertical diameter, on the first day after the operation in six cases. It sometimes occurs after the cyclodialysis of Heine (1936), but in these instances had no particular consequences for the operated eye, as in every case it was totally resorbed after a few days with the usual therapy.

Iritis.--A mild iritis, probably caused by the diathermy, occurred in four cases. In these, the post-operative treatment had to be prolonged for nearly 10 days, but in not one of them was there any formation of a posterior synechia, nor was there any reduction of visual acuity in the operated eye.

Effects on Visual Acuity and Field of Vision.-In several cases observed over a period of 9 months after the operation the visual acuity was not improved to the same degree as the intra-ocular pressure. The cases of congenital, chronic, and simple glaucoma which showed improvement are set out in Table II.

TABLE II

EFFECTS ON VISUAL ACUITY

Type of Cilaucoma

Visual Acuity

Before Operation After Operation

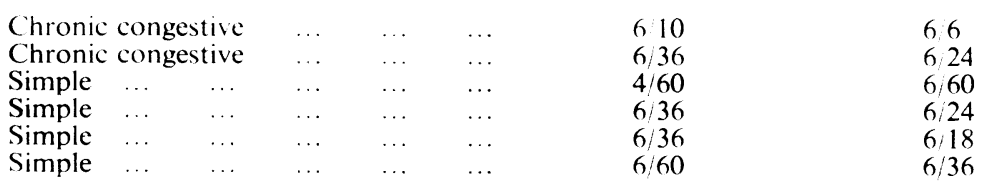

This improvement was not very considerable because in most of these cases visual acuity had been much reduced before operation by pathological changes in the optic nerve due to the increased intraocular pressure. 
Of four cases of almost absolute glaucoma, vision improved in two from perception of light at $5 \mathrm{~m}$. to $1 / 60$, and in the other two from perception of light at $2 \mathrm{~m}$. to $0.3 / 60$.

Of thirteen cases of secondary glaucoma, there was no improvement of vision in twelve, but all these also had corneal opacities which prevented the assessment of any possible recovery of vision.

A fairly satisfactory recovery of vision was noted in the one case of hydrophthalmos; visual acuity improved from $4 / 60$ before to $6 / 36$ after the operation, and the field of vision was enlarged by 15 to $20^{\circ}$.

\section{Discussion}

Our operative technique combines non-perforating cyclodiathermy and cyclodialysis circumscripta. Dominguez (1948) applied nonperforating cyclodiathermy with the cyclodialysis of Heine (1936), but our method of cyclodialysis is different. A combination of non-perforating cyclodiathermy with iridodialysis (Ćavka, 1944), evolved from our experience with rabbits' eyes, gave better results in reducing the intra-ocular pressure than the application of nonperforating cyclodiathermy alone. Our technique in cyclodialysis circumscripta differs from the classical operation of Heine in that the scleral incision is made into the projection of the anterior part of the ciliary body, i.e., into the muscular portion of the ciliary body and not into the pars plana. This method is easier in as much as there is no danger of perforating the ciliary body during the incision or trephining of the sclera. It is necessary to peel off nearly twice as much of the surface of the ciliary body as in Heine's operation, but it seems to act more quickly in reducing the intra-ocular pressure.

Besides its favourable results in cases with primary and secondary glaucoma in reducing increased intra-ocular pressure to normal, there were few, if any, post-operative complications. Those complications which did occur were slight and quickly eliminated with the usual therapy. In view of the satisfactory results obtained, this method can be applied in cases of primary and secondary glaucoma, as well as of absolute glaucoma.

\section{SUMMARY}

Non-perforating cyclodiathermy with cyclodialysis circumscripta was performed in thirty cases of primary and thirteen cases of secondary glaucoma. In ten cases the operation was performed bilaterally. The intra-ocular pressure was reduced to normal in 41 eyes (76 per cent.), and in the remaining twelve it was reduced but without becoming normal. 
In six cases slight hyphaema appeared in the anterior chamber, and in four cases a mild iritis was seen post-operatively, but all these complications were completely cured.

\section{REFERENCES}

Albaugh, C. H., and DunPhy, E. B. (1942). Arch. ophthal., Chicago, 27, 543.

CAVKa, V. (1944). Klin. Mbl. Augenheilk., 110, 525.

Desvignes, P., and NAudin (1948). Arch. Ophtal., Paris, 8, 589.

DOMINGUEZ, D. D. (1948). Arch. Soc. oftal: hisp.-amer., 8, 117.

GrüTER, W. (1949). Klin. Mbl. Augenheilk., 114, 466.

HEINE, L. (1936). Ibid., 97, 721.

MARR, W. G. (1949). Amer. J. Ophthal., 32, 241.

RANKIN, . (1942). Quoted by Spaeth (1948).

Spaeth, E. B. (1948). "Principles and Practice of Ophthalmic Surgery", 4th ed. Kimpton, London.

VoGt, A. (1936). Klin. Mbl. Augenheilk:; 97, 672.

WEEKERS, L., and WEEKERS, R. (1945). Ophthalmologica, Basel, 109, 212.

and HeINTZ, A. (1949). Bull. Soc. belge Ophtal., No. 92, p. 210.

WeVE, H. (1933). Proc. XIV int. Congr. Ophthal., Madrid 1933, vol. 4, pt. 2, p. 100. 